\title{
REPRESENTAÇÕES MEDIÁTICAS DO RURAL BRASILEIRO EM UMA PERSPECTIVA PÓS-IDENTITÁRIA: o devir-rural e a experiência do Cinejordão
}

\section{MEDIA REPRESENTATIONS OF BRAZILIAN RURAL IN A POST-IDENTITARY PERSPECTIVE: the becoming-rural and the experience from the Cinejordão}

\author{
Eduardo Yuji YAMAMOTO ${ }^{1}$
}

Resumo: O texto articula fragmentos teóricos para problematizar a representação mediática do rural brasileiro. Para isso, a categoria do rural é pensada para além das formas identitárias historicamente consolidadas, mais precisamente, como zona de conflito, de evocação de vidas, comunidades, modos de existência que precede, acomete ou sucede o enunciatário, constituindo uma trama de sentido que o implica, vincula ou responsabiliza. O texto é estruturado em dois momentos: no primeiro, são apresentadas experiências comunicacionais que, de alguma maneira, tentaram organizar as populações do campo em torno de um imaginário ou ideologia; em um segundo momento, reivindica-se um princípio estético capaz de viabilizar uma implicação às obras provenientes do projeto Cinejordão (SETI/Unicentro-PR) que tem como objetivo produzir representações do rural através do cinema.

Palavras-chave: Comunicação Rural; Comunicação Comunitária; Imagem Política; Extensão Universitária.

\begin{abstract}
The text articulates theoretical fragments to problematize the media representations of the Brazilian rural. For this, the category of rural is thought beyond the identity forms historically consolidated, more precisely, as a zone of conflict, of evocation of lives, communities, modes of existence that precedes, attacks or succeeds the viewer, constituting a web of meaning that implies, binds, or makes him responsible for. The text is structured in two moments: in the first, it presents communication experiences that, somehow, tried to organize the Brazilian countryside around an imaginary or ideology; in a second moment, an aesthetic principle is claimed, capable of making possible an implication to the works coming from the Cinejordão project (SETI/Unicentro-PR) that aims to produce representations of the rural through the cinema.
\end{abstract}

Keywords: Rural Communication; Community Communication; Political Image; University Extension.

\footnotetext{
${ }^{1}$ Doutor em Comunicação e Cultura pela Universidade Federal do Rio de Janeiro (UFRJ/RJ). Professor Adjunto $\mathrm{B}$ da Universidade Estadual do Centro Oeste (UNICENTRO/PR). E-mail: yujieduardo@gmail.com
} 


\section{miDiA \\ ec DiAno}

\section{Introdução}

No último número da revista Mídia e Cotidiano, dedicada ao tema da comunicação comunitária, a pesquisadora Raquel Paiva (2017) observou a necessidade de refundar a área haja vista o avanço de práticas sociais excludentes e antidemocráticas nos últimos anos. Em um contexto marcado pela sofisticação tecnológica dos meios, pela popularização de redes sociais digitais e dispositivos móveis de comunicação, Paiva destaca o elemento deficitário da comunicação social, isto é, a incapacidade de reconhecimento do outro, de sensibilizar-se pelas demandas de grupos vulneráveis, reivindicando a urgência por formas comunicacionais críticas e inclusivas.

Nesse cenário, a tentativa de democratizar as representações minoritárias, de dar visibilidade às suas demandas e constituir uma audiência menos passiva, é o que tem impulsionado alguns projetos de comunicação comunitária a um duplo esforço: por um lado, construir coletivamente uma estrutura técnica e cognitiva de comunicação; por outro, assegurar tanto a permanência dessa estrutura ao longo do tempo, quanto a ampla participação comunitária. Ao menos é o que se tem evidenciado em propostas comunicacionais de diferentes vertentes (cinema, fotografia, comunicação popular, alternativa, comunitária, rural, etc.) que buscam, estrategicamente, discursivizar essas demandas.

Um projeto que compartilha dessas preocupações é o Cinejordão, realizado pelo grupo de pesquisa Laboratório de Estudos de Comunicação e Biopolítica (LABBIO/CNPq) da Universidade Estadual do Centro Oeste (Unicentro), com subsídios da Secretaria da Ciência, Tecnologia e Ensino Superior do Estado do Paraná (SETI-PR). Assim como muitos projetos de comunicação comunitária, o objetivo é dar visibilidade às representações de uma comunidade específica - historicamente denominada como rural -, através de narrativas cinematográficas.

A escolha desse código como forma de expressão comunitária deve-se a algumas particularidades: primeiramente, a possibilidade dada pela linguagem do cinema de pôr em movimento a imagem dos sujeitos aí implicados (suas histórias, utopias, vidas e destinos comuns), seja para reafirmar uma identidade, seja para suscitar debates ou disputas acerca dela. A imagem, como constituinte dessa linguagem, gera um sentimento (e, portanto, a aparição) de comunidades, pois, como observou Jacques 
Rancière (2012, p. 99) "a imagem cria certo senso de realidade, certo senso comum. Um ‘senso comum' que é, acima de tudo, uma comunidade de dados sensíveis". Em segundo lugar, a expectativa de disponibilizar uma forma alternativa de comunicação comunitária para além do código jornalístico, uma forma - talvez - mais afinada ao consumo informacional contemporâneo caracterizado pela instantaneidade e pelo forte apelo audiovisual. Por fim, a tentativa de buscar, nos estudos do cinema e da imagem, contribuições (ou mesmo respostas) para as questões da representação, da participação e do engajamento aos problemas de minorias discursivas como as populações rurais.

Nos encontros entre graduandos, profissionais da comunicação e a comunidade da Vila Jordão (bairro camponês, onde o projeto é realizado), questões basilares da comunicação comunitária - como aquelas evidenciadas acima por Paiva - têm sido colocadas. Dessas, sistematizamos dois conjuntos de problematizações referentes à constituição histórica dessa comunidade e ao uso do cinema enquanto matriz técnica e cognitiva do trabalho comunicacional. São eles: 1) o que é o rural hoje? 2) como o cinema poderia ampliar as demandas das comunidades rurais, bem como o amplo engajamento e participação para os problemas do campo.

Nas linhas que se seguem, esses dois conjuntos de problemáticas serão desenvolvidos a partir de argumentos que visam refundar politicamente o rural. Parte-se da premissa de que, historicamente, o rural constituiu-se como o outro da modernidade, seja a partir de um ponto de vista negativo (a imagem do atraso, da ignorância a serem superadas), seja positivo (foco de resistência ao avanço da sociedade urbana industrial). Porém, ao contrário de um julgamento que percebe tal ambiguidade ora como incoerência social, ora como inconsistência histórica, aqui ela será evocada como condição para a sua politização contemporânea - uma reserva de imagens e dissensos.

\section{Imagens do rural brasileiro}

Apesar de suas particularidades, é possível estabelecer pontos de aproximação epistemológica entre as áreas da comunicação comunitária e da comunicação rural no que se refere às representações que subjazem o desenvolvimento de suas praxiologias no Brasil. Se a primeira consolidou uma parte significativa de seus estudos na imagem dicotômica de sociedade de Ferdinand Tönnies - Gemeinschaft x Gesellschaft 
(comunidade x sociedade) -, de modo semelhante, a comunicação rural incorporou essa estrutura enquanto matriz teórica e metodológica. Enno Liedke Filho denominou a operacionalização dessa estrutura como teoria da modernização, baseada em uma divisão social assimétrica entre o campo e a cidade, com a positivação da segunda em detrimento da primeira.

A Teoria da Modernização concebe o processo de desenvolvimento como uma transição de uma sociedade rural tradicional para uma sociedade industrial moderna [...] Essa transição, quando incompleta, acarreta a coexistência de ambas as formas societárias dentro de uma mesma sociedade nacional, caracterizando-a como uma sociedade dual. Ressalte-se que esta tese teve ampla aceitação internacional na sociologia do desenvolvimento, assim como no âmbito das agências internacionais como a UNESCO (LIEDKE FILHO, 2005, p. 386).

Para o sociólogo mexicano, Rodolfo Stavenhagen (1981), essa imagem de "sociedade dual" disseminou-se rapidamente na América Latina desde meados do século XX como forma explicativa para as disparidades entre as regiões do país ganhando a adesão de muitos intelectuais, professores e pesquisadores, mesmo com as críticas à ideologia e às inconsistências teóricas que a caracterizavam. Pois, além de equivocado, dizia Stavenhagen, essa imagem justificava a intervenção de agentes externos - sob o argumento do desenvolvimento do país - e pouco viabilizava as condições para a luta camponesa e a reforma agrária.

\footnotetext{
Não há dúvida de que em todos os países latino-americanos há grandes diferenças sociais e econômicas entre as áreas rurais e urbanas, entre indígenas e não-indígenas, entre a massa de camponeses e as pequenas elites urbanas e rurais, e entre regiões muito atrasadas e outras bem desenvolvidas. Também é evidente que em algumas áreas atrasadas ou isoladas existem grandes latifúndios em que as relações sociais e de trabalho entre os camponeses e o proprietário (ou seus representantes) tem todas as características de servidão, se não de escravidão. Essas diferenças, contudo, não justifica o uso do conceito 'sociedade dual', por duas razões principais: em primeiro lugar, porque os dois pólos são o resultado de um único processo histórico, e em segundo lugar, porque as relações mútuas que conservam entre si as regiões e os grupos 'arcaicos' ou 'feudais' e 'modernos' ou 'capitalistas' representam o funcionamento de uma só sociedade global de que ambos os pólos são partes integrantes (STAVENHAGEN, 1981, p. 16).
}

É nesse contexto que propomos oferecer elementos críticos para problematizar as representações comunicacionais brasileiras sobre $\mathrm{o}$ rural. $\mathrm{O}$ âmbito dessa problematização limita-se à produção teórica de duas áreas da comunicação: a comunicação rural (ou extensionista, a comunicação popular ou comunitária do 
campesinato) e o cinema ${ }^{2}$. Desde a imagem subentendida sobre as comunidades do campo nas atividades extensionistas da comunicação rural às imagens ressignificadas do campesinato pelas produções cinematográficas dos anos de 1960, objetiva-se ampliar o debate sobre a representação mediática do rural no Brasil, bem como pensar as formas de engajamento às questões do campo (exploração do trabalho, reforma agrária, acesso à cidadania, preservação ambiental etc.).

De acordo com o geógrafo Ivair Gomes (2013), invariavelmente, a construção do rural tem se definido a partir da cidade (zona urbana), seja em termos objetivos (distância de centros urbanos, o tempo de viagem, o local de trabalho, densidade populacional, etc.) ou subjetivos (modo de vida, cultura, etc.). O problema dessa construção não é a alteridade em si ou os predicados que incidem sobre os lados dessa divisão, mas a objetificação do rural, isto é, como lugar desprovido de subjetividade, logo, de subjetivação.

A tradicional distinção entre as zonas urbanas e rurais no interior de um país são baseadas no pressuposto de que as zonas urbanas, não importa como elas são definidas, fornecem um modo de vida diferente e, geralmente, um nível de vida mais 'elevado' do que os encontrados em áreas rurais [...] É com as características relacionadas à densidade populacional e às distâncias dos centros urbanos que eles tem feito a distinção rural/urbana, em detrimento a aspectos sociais e culturais que surgem apenas de forma secundária em suas políticas (GOMES, 2013, p. 95).

O reconhecimento do rural enquanto objeto tem reduzido o entendimento da comunicação rural a uma prática meramente difusionista. A comunicação, nesse sentido, limita-se à domesticação das forças do campo - suas relações sociais e seus modos de vida - e ao disciplinamento de corpos para uma única produtividade, isto é, a economia, a produção e a troca material.

Das revisões atualmente disponíveis sobre a comunicação rural no Brasil, destaca-se a pesquisa de Ricardo Duarte e Jeferson Boechat Soares (2011) que traçam um panorama dessa atividade no país desde as suas origens no final do século XVIII. Para os autores, devido à materialidade que constitui esse lugar (fonte direta do trabalho, meio de subsistência familiar, da acumulação de riquezas etc.) e aos agentes

\footnotetext{
${ }^{2}$ Excluiu-se aqui, por exemplo, os estudos sobre rádio e TV, publicidade e propaganda, comunicação organizacional e jornalismo já que o universo abrangido por essas áreas, além de transcender as dimensões deste texto, reiteram as representações do rural já tratadas por essas duas áreas.
} 
que entram nessa disputa, os projetos que incidem sobre o rural revelam maneiras divergentes de concebê-lo - e, portanto, agenciá-lo -, ora retraindo a sua autonomia (e, assim, legitimando a entrada de agentes externos), ora desafiando a sua passividade. Nesse último caso, os autores evidenciam abordagens teóricas que desfazem a imagem passiva dessas populações, por exemplo, problematizando como "os agricultores produzem sentido sobre as mensagens extensionistas - a maneira como são construídos os discursos políticos na comunicação rural” (DUARTE; SOARES, 2011, p. 411).

Apesar dessas abordagens elucidarem o protagonismo comunicativo das populações rurais e destacarem dimensões importantes da comunicação social - "os aspectos sociais e culturais" que Gomes diz terem sido preteridos nas definições do rural -, o desenvolvimentismo ainda persiste como gramática fundadora.

\begin{abstract}
A Comunicação Rural nasce como mudança paradigmática da transferência em si para a troca de saberes, que traz novos olhares para velhos problemas: 'comunicação comunitária', 'comunicação participativa e desenvolvimento local, integrado e sustentável', 'comunicação e redes solidárias', 'comunicação e ecologia no campo', 'educação ambiental', 'comunicação nas organizações rurais', entre outros. No entanto, essa mudança paradigmática também representou uma espécie de 'cisão política', que dura até hoje: de um lado, alguns que preservam o meio ambiente a partir da comunicação comunitária (comunicação rural); do outro, aqueles que buscam o crescimento do meio rural através do método do agronegócio (extensão rural e assistência rural). No centro desses atores sociais, está a noção de desenvolvimento como transposição do tradicional para o moderno. Essa concepção tem atravessado décadas, sendo o norte das ações institucionais, das pesquisas acadêmicas e dos projetos governamentais no meio rural (DUARTE; SOARES, 2011, p. 404).
\end{abstract}

Igualmente, nas produções cinematográficas brasileiras, a disputa pela conceituação do rural, bem como de sua produção de sentido, tem-se mostrado bastante complexa, pois apresenta uma diversidade de cenários, sujeitos e valores culturais em conflito. Em uma formação social cujos avanços técnicos sofisticam as relações de trabalho; em que a variável do domínio material (a posse dos meios de produção) complexifica a relação de poder com as representações simbólicas; e em que, conforme Duarte e Soares (2011, p. 414), "valores midiatizados" são incorporados à vida de comunidades rurais, "hibridizando ou reconvertendo sua cultura tradicional e forma de pensamento com os valores e costumes da forma de vida urbana", pensar nas modalidades políticas as quais tais representações do rural produzem seus 
agenciamentos dão a dimensão das forças e estratégias (estéticas, discursivas, simbólicas etc.) que estão em curso nesse espaço.

Assim como na comunicação rural, a ideia de criar representações culturais que legitimem ações políticas sobre o campo - como aquelas criticadas por Stavenhagen tem sido comum no Brasil através do cinema. O filme Jeca Tatu (1959), dirigido por Milton Amaral e estrelado pelo comediante Amácio Mazzaropi, é exemplar no que se refere ao consentimento de uma necessidade tecnológica (o difusionismo) a partir de uma forma cultural. O protagonista, originário da literatura popular de Monteiro Lobato, é representado como um matuto ingênuo e preguiçoso que, ao entrar em conflito com um latifundiário local, busca em um agente externo (deputado Doutor Felisberto) as condições para sua superação sem, contudo, legar formas de organização para a classe trabalhadora ou de mediação política impessoal.

O filme, mais do que simplesmente expor as forças que presidem o mundo do trabalho rural até meados do século $\mathrm{XX}$ - quais sejam, a família camponesa, o latifúndio, os operadores políticos do sistema institucionalizado de poder -, intensifica o caráter negativo do trabalhador do campo - materializado no Jeca inculto e indolente tanto quanto o mundo da vida em que todos esses personagens estão mergulhados, um mundo atrasado, simplório, conservador, até mesmo irracional (em que os conflitos são resolvidos pelo uso da violência). A contraposição entre a cidadezinha do interior e a vida glamourosa em São Paulo; entre o carro de boi que trafega solitário na estrada de chão e as ruas abarrotadas de automóveis da capital, entre o carisma populista do Jeca e a racionalidade política do deputado Doutor Felisberto, revelam a valoração desigual em favor da cidade e estabelecem as condições representativas para a anuência de modelos teóricos como o da modernização.

A entrada de outros agentes sociais preocupados com a representação negativa do rural brasileiro a partir de 1960 acresceu a ela uma outra camada de significação. Da imagem da ingenuidade e da subserviência, ele passou a operar em uma chave de leitura mais complexa, ora como substrato do imaginário popular para a crítica aos projetos políticos da burguesia nacional, ora como fundamento para a proposição de uma estética subversiva e singular. Filmes como Vidas Secas (Nelson Pereira dos Santos, 1963); Deus e o Diabo na Terra do Sol (Glauber Rocha, 1964); O Dragão da Maldade Contra o 
Santo Guerreiro (Glauber Rocha, 1969); Iracema - Uma Transa Amazônica (Jorge Bodanzky e Orlando Senna, 1975); São Bernardo (Leon Hirszman, 1980); Cabra Marcado para Morrer (Eduardo Coutinho, 1984), entre outros, além de evidenciarem a multiplicidade das figuras políticas do rural brasileiro, agenciaram desse substrato popular uma forma cultural diferenciada - a chamada estética da fome do Cinema Novo. Outros filmes como Lavoura Arcaica (2001), de Luiz Fernando Carvalho, vêm dando continuidade à representação do rural enquanto objeto de grande complexidade desfazendo àquela imagem de conformismo e apatia que ainda a atravessa.

\section{Do dual ao singular}

Uma das análises mais significativas sobre a representação cinematográfica do rural brasileiro foi realizada por Célia Aparecida Ferreira Tolentino (2001). Ao apresentar a imagem negativa do rural que vai desde meados da primeira metade do século XX até 1980, Tolentino encontra em cineastas como Nelson Pereira dos Santos, Glauber Rocha e Eduardo Coutinho, os sujeitos que elevarão o rural a uma forma politizada, seja a partir de um enquadramento estético inovador (realismo), seja a partir das figuras (outrora moralmente rebaixadas) do cangaceiro, do sertanejo, do jagunço, do beato e do retirante.

Para Tolentino, se o cinema brasileiro pré-1960 se preocupou em compartimentar o rural, estabelecendo uma fronteira entre a cidade e o campo, tal como a imagem oferecida pela teoria da modernização, a produção cinematográfica que sucedeu esse período não apenas contestou essa fronteira, como colocou a população do campo como protagonista desse processo.

[...] fundamentalmente, a grande marca do cinema politizado dos anos 60 é a descompartimentação. A intenção de compreender o país em torno do projeto de uma sociedade sem classes subvertia a leitura burguesa da filmografia paulista e reescrevia nossa relação com o rural. O homem brasileiro, visto na figura do homem pobre do campo, tornava-se grande, muito distinto da identidade que nos conferira Macunaíma: pleno de lealdades, íntegro, valente, disposto a empenhar a sua vida por uma ideia ou por um líder, 'imaculado do imperialismo' e defensor das formas coletivistas de vida. $\mathrm{O}$ sertanejo voltava a ser, antes de tudo, um forte que redimiria a nação e reescreveria nossa inserção no mundo (TOLENTINO, 2001, p. 305). 


\section{míDiA

No entanto, com a intensificação do regime militar no período, a produção política do rural no cinema brasileiro desacelerou, restando as "alegorias do desengano", um conjunto de produções que refletiam o "triste balanço das utopias, uma interlocução com os projetos anteriores, numa chave pessimista" (XAVIER apud TOLENTINO, 2001, p. 233).

A sequência final de Cabra Marcado para Morrer (1984), em que Elizabeth Teixeira deixa o município de São Rafael, no estado do Rio Grande do Norte, para morar com seus dois filhos, Abraão e Carlos, em Patos, na Paraíba, talvez sintetize esse momento reflexivo, ou seja, o esforço de "entender o país como um todo orgânico, agora em direção a encontrar os caminhos do fracasso da utopia socialista de uma 'realidade que não tinha operado conforme as expectativas'” (XAVIER apud TOLENTINO, 2001, p. 233).

Mas se a morte de João Pedro Teixeira pelas forças da modernização esvaziou a luta camponesa, assim como arrefeceu a esperança dessa população por democracia e justiça social - no filme, Elizabeth não chegou a encontrar seis de seus dez filhos desaparecidos -, as figuras políticas elaboradas pelo Cinema Novo deixaram também algo de positivo: a inquietação do rural, a disputa por sua narrativa e destino. Para Tolentino, a despeito daquela compartimentação das representações do rural que dominaram o imaginário cultural brasileiro, foi possível tomar "as manifestações messiânicas e cangaceiras como formas de rebeldia primitivas que indicassem possíveis trajetórias para a inconformidade e consciências políticas" (TOLENTINO, 2001, p. 173).

Esse fato tem encorajado a elaboração de formas contemporâneas de politização do rural brasileiro por meio de uma chave menos pessimista, não obstante, em sintonia com as condições históricas vigentes. A recente popularização de dispositivos de captação, produção e edição audiovisual geram uma situação material favorável para a produção de narrativas variadas sobre o rural. É verdade que essa situação nem sempre se oferece a todas as populações do campo; e é aí que a comunicação rural (extensiva, popular ou comunitária) adquire grande importância no trabalho de agenciamento de recursos (materiais e humanos) que viabilizem tal situação. 


\section{míiA
eCOti
DiAno}

Outro elemento importante para pensar contemporaneamente a politização mediática do rural advém de uma crítica sobre o conceito em voga, isto é, ao fato de, historicamente, conceber-se enquanto objeto da cidade (o outro da modernidade). Essa condição tanto favoreceu o desenvolvimento de um imaginário rural a partir de figuras não-urbanas, quanto legou certo pessimismo dada a violência e censura que incidiu sobre algumas figuras: o cangaceiro, o líder camponês, o retirante etc.

Ora, esse pessimismo está relacionado à consciência da não realização de uma narrativa (a do campesinato brasileiro), do desejo interrompido de sua realização histórica por ocasião do golpe civil-militar. Um desejo ambíguo que esconde, sob a ação politizadora do campesinato, uma atitude contrária, chamada de "policial" por Rancière (2010, p. 428), dada a insistência por enrijecer as fronteiras imaginadas do rural, “[...] a saturar a relação dos corpos e das significações, das partes dos lugares e dos destinos".

Desse desejo, portanto, faz-se necessário evidenciar a atitude politizadora pela contraefetuação do pessimismo em criação, pela reabertura dos intervalos que separam "os nomes de sujeitos e os seus modos de manifestação dos corpos sociais e das suas propriedades" (RANCIÈRE, 2010, p. 428). Essa condição mostra-se hoje favorável dada a identidade não acabada (ou não realizada) do rural e de suas figuras em gestação, abrindo as portas para um devir-rural ou para um rural-que-vem.

É justamente dessa elaboração que se pode conceber um conceito per se do rural, forjado na multiplicidade de histórias, falas, intenções, indignações ou vidas singulares. Isso significa sair de uma necessária oposição compartimentada com a cidade para uma condição de apagamento de fronteiras, de coabitação e reciprocidade. O que importa nessa elaboração não é tanto a figura que dali emerge, mas a "rebeldia primitiva" que desperta, a capacidade de uma imagem de instabilizar as distribuições de corpos e significações, de abalar as fronteiras e identidades dadas ou preestabelecidas, de convocar diferentes corpos - pertencentes a diferentes posições e proveniências - a povoarem e intensificarem esse espaço do rural. Um gesto que Cezar Migliorin (2011) chamou de "imagem política".

A existência de uma imagem política se faz quando a luz que faz parte da máquina-cinema opera uma composição significante e sensível entrando na própria variação do mundo sem se fiar na centralidade do sujeito ou da comunidade, tampouco em uma teleologia histórica ou narrativa subordinando sujeitos e imagens ao texto (MIGLIORIN, 2011, p. 17). 
Para o autor, essa composição deve ser capaz de desestabilizar a imagem presente do rural - as figuras identitárias, as relações de sentido historicamente consolidadas - para, através de múltiplos agenciamentos temporais, convocar novas produções. Não se nega, obviamente, a atualização das figuras políticas do rural cinemanovista nessas novas produções; ao contrário, realiza-se a sua profecia agenciando-as "como um ordenador do passado ou do futuro, mas como uma variação em que passado e futuro são convocados não como informação, mas como intensidades produtivas" (MIGLIORIN, 2011, p. 17-18).

Esse processo deve ser capaz de provocar no público (ou enunciatário) uma espécie de esvaziamento subjetivo através da evocação de vidas, comunidades, modos de existência que o precedem, o acometem ou o sucedem, constituindo uma trama de sentido que o implica, vincula ou responsabiliza.

Um exemplo de imagem política no cinema rural é a fotografia do corpo de João Pedro Teixeira, protagonista ausente de Cabra Marcado para Morrer (Eduardo Coutinho, 1984).

\begin{abstract}
Embora não tenha sido encomendado ou realizado pela família, e sim pelo fotógrafo de um jornal, empenhado talvez em registrar evidências do crime, o retrato mortuário de João Pedro não deixa de resistir contra o desaparecimento da pessoa. Única imagem que dele teria restado, a foto prova que o assassinato não pôde aniquilar inteiramente os rastros de sua passagem. Importante assinalar que, neste caso, a morte se liga a um projeto de apagamento político, de fazer calar, com violência, o trabalho de ruptura social liderado por João Pedro no campo. Por isso, presentificá-lo, criar para o morto outro estado de visibilidade e de presença no mundo, fazer o trabalho de luto, em suma, é também perpetuar a memória de uma luta coletiva, oferecendo-a para sua posteridade (MESQUITA, 2015, p. 43).
\end{abstract}

Aqui, Claudia Mesquita destaca uma imagem que fica retida na memória social brasileira (o corpo abatido de João Pedro Teixeira), um acontecimento visual que, conforme Migliorin (2011), entra na própria variação do mundo social contemporâneo, instabilizando a imagem consentida ou apaziguada do rural brasileiro ao "presentificar" a Liga Camponesa de Sapé. Sem se fiar na centralidade da classe camponesa, essa imagem se avoluma e endereça ao público indiferenciado certa cumplicidade.

Nessa sequência, as fronteiras são derrubadas - na foto de João Pedro não é possível identificar as marcas que separam seu corpo de todos os outros que o assistem; não há aí um corpo rural, por exemplo. Mas, além de João Pedro, outros corpos vão 


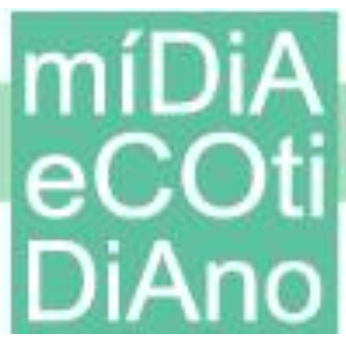

aparecendo e encurtando a distância que os separam do presente (de nós), exigindo uma resposta. Eis a força de composições como essa: dar a ver certos corpos não como objetos sobre os quais os olhos decidem sua retenção, mas como sujeitos que olham, desafiam e subjetivam o espectador.

O problema dos engajamentos, diz Rancière (2012, p. 94), não é que "vemos corpos demais a sofrerem na tela", pois, na verdade, vemos um conjunto de imagens selecionadas pelos sistemas de informação (media) que recortam ou traduzem o sofrimento para um nível de tolerância social. Se as imagens fazem alguma diferença essa se dá pela capacidade de eliminar essas distâncias e compartimentações, de dessaturar certa distribuição para fazer emergir a responsabilidade por esses corpos que, frequentemente, se quer longe do campo visual ou mneumônico.

No entanto, é preciso mais sensibilidade que crueza para alcançar tais efeitos; para produzir uma relação (uma sintonia fina) entre o que vemos e o que nos vê - como lembra Georges Didi-Huberman (2010) - ou despertar suficiente "curiosidade" naquele que vê (RANCIÈRE, 2012) a fim de que esse não desista da imagem. Por vezes, esse senso de responsabilidade pelo que vemos advém após uma tragédia (uma humilhação, uma morte, um genocídio etc.), mas seria o caso de esperá-la? Haveria outros modos de sensibilizarmos pelo que vemos, de derrubarmos as fronteiras imaginadas do rural e promovermos novas vinculações que não seja ao custo de algumas vidas?

Um modo de sensibilidade (ou de responsabilidade) que o projeto Cinejordão tem desenvolvido consiste na elaboração e recepção de obras cinematográficas de natureza comunitária, ou seja, produzidas a partir da própria comunidade e exibidas para todo o município. Como se verá na sequência, essa experiência cinematográfica coloca em interação diferentes sujeitos estimulando encontros improváveis (como entre estudantes universitários, profissionais de comunicação e filhos de trabalhadores do campo) - gesto que tanto busca encurtar a distância que separa aquele que filma (sujeito) daquele que é filmado (objeto), quanto alcançar uma profundidade psicológica e social, inspirando histórias e argumentos mais complexos, isto é, para além da oposição entre campo e cidade e suas distribuições convencionais.

No ato de criação de um roteiro, de uma personagem, da resolução de um conflito etc., irrompe um ambiente de habitação comum em que todos se 
responsabilizam em efetuá-lo na obra cinematográfica, um rural não como lugar identitário, mas de multiplicidades. A obra, dada a expectativa de exibição ao público, gera um sentimento de trabalho bem feito e a prática colaborativa, o intercâmbio de informações técnicas sobre cada detalhe da produção. Como essa produção acontece apenas dentro da comunidade intensifica-se aí a procura por habilidades específicas e o aperfeiçoamento de dispositivos sociais que viabilizam o convívio com as diferenças.

Reivindicar um conceito vazio ou demasiadamente fluido de rural implica o desafio de criar constantes estratégias de subjetivação coletiva. Mas também de encarar a crítica que percebe esse gesto como alienação ou conformismo diante de uma forma cultural hegemônica (uma crítica justa mas que permanece alheia à vontade de purificar a classe camponesa). Sobre essa crítica, observa-se que rejeitar o hibridismo que atualmente atravessa as figuras do rural brasileiro, não significa apenas negar a multiplicidade de criações nesse meio, mas afastar-se da própria realidade dessas populações.

\section{Cinejordão}

O projeto Cinejordão é desenvolvido em um bairro rural e periférico do município de Guarapuava (PR) - a Vila Jordão - que possui uma das menores rendas per capita da cidade $^{3}$. Integram o projeto pesquisadores da Unicentro, discentes dos cursos de Publicidade \& Propaganda, Jornalismo, Artes, além de publicitários, pedagogos e estudantes de duas escolas públicas do campo.

O objetivo é viabilizar a emergência de múltiplas representações do rural a partir de ações como: exibição e debate de filmes brasileiros com a temática do campo; promoção de oficinas de fotografia e cinema para estudantes de escolas públicas rurais; produção experimental de obras audiovisuais a partir de uma imersão na comunidade.

Já em seu início, quando a equipe se planejava para as atividades (seleção de filmes, temas, assuntos a serem abordados na comunidade), o pressuposto de que o rural é dotado de características intrínsecas foi problematizado pela observação de que essas,

\footnotetext{
${ }^{3}$ A renda, nesse bairro, segundo o relatório do Plano Diretor do Município, referente ao ano de 2013, é de R \$ 417,92. (Disponível em http://concidade.com.br/concidade/pages/tgpdf. Acesso em 28 de jun. de 2017).
} 


\section{míDiA \\ ecc \\ DiAno}

historicamente, são oferecidas pelos medias através de estereótipos. Não obstante, esses enquadramentos poderiam não apenas reduzir as vidas ali representadas - seu contexto histórico e social, a profundidade e intensidade dos conflitos existenciais etc. - como, posteriormente, levar a uma simplificação de todo o projeto, pois suprimiria seu intento experimental e, portanto, a possibilidade de ruptura e descoberta desse lugar.

A ideia de um rural não consolidado, isto é, em estado de variação (em devir), pareceu razoável à equipe enquanto disposição ao trabalho e ao entendimento sobre a Vila Jordão. Foi munido dessa disposição que a equipe tanto elaborou as oficinas de fotografia e cinema nas escolas, como, atualmente, vem produzindo roteiros para as suas produções audiovisuais.

Sobre as oficinas, observa-se que essas consolidaram-se como atividade chave do projeto, pois além de fornecerem as condições técnicas e materiais para a produção de narrativas sobre o cotidiano desses estudantes (suas utopias, desejos, indignações e alegrias etc.), acabaram por aproximar a equipe universitária das famílias camponesas. Essa aproximação deu-se pela troca de conhecimento entre esses dois grupos e gerou, para ambos os lados, tanto confiança como solidariedade, elementos básicos para a produção documental.

Ainda, as oficinas possibilitaram um entendimento preliminar da comunidade através da análise discursiva de argumentos e roteiros escritos pelos estudantes. Esses textos apresentaram elementos simbólicos importantes como o fato de suprimirem a figura de um protagonista nos enredos - os personagens principais eram grupos de crianças ou de jovens -, o que evidenciava um senso de interdependência, algo frequente em outros momentos e atividades do grupo. Tal evidência refuta a ideia de uma homogeneização identitária e afirma ali o reconhecimento do outro enquanto figura indispensável à realização de obras comuns, seja um curta-metragem, seja a própria individuação. Tal fato foi reiterado por meio de análises sobre os quatro curtasmetragens produzidos pelos estudantes. Em nenhum deles se constatou qualquer passividade ou desejo de unificação identitária, mas a alegria em superar coletivamente um obstáculo ou experienciar uma transformação. Um dos curtas-metragens, por exemplo, é centrado na presença de figuras fora do domínio comunitário (fantasmas, alienígenas etc.) as quais instigam o grupo a saírem desse domínio rumo ao 


\section{míDiA

desconhecido, estimulando as descobertas. A presença de um alienígena na comunidade - que bem poderia ser uma representação imediata da equipe universitária ${ }^{4}$ - remete ao dilema contemporâneo que incide sobre todos os grupos sociais, mais drasticamente sobre as minorias: resistir e enfrentar os agentes econômicos, políticos e culturais que promovem as diásporas no campo.

A evidência desses elementos simbólicos, acrescidos pela reflexão teóricoconceitual da comunicação comunitária e do cinema, além dos problemas estruturais que afligem atualmente as populações rurais - aumento da exploração imobiliária, da expansão da agroindústria, do desemprego e precarização do trabalho no campo, das diásporas etc. - possibilitou ao projeto o desenvolvido de roteiros para a produção de obras audiovisuais sobre a comunidade. O ponto de partida dessas obras é a tentativa de instabilizar qualquer imagem consensual do rural brasileiro. Pretende-se que essas imagens, ao lado das imagens produzidas pelos estudantes, estimulem o debate sobre essas populações a partir de múltiplas frentes e enfrentamentos: crítica àqueles problemas estruturais, evocação de vidas e acontecimentos esquecidos, mobilização de afetos através das estratégias de subjetivação promovidas pelos entrevistados, entre outros. Dois desses roteiros, atualmente em fase de produção, buscam povoar e intensificar a imagem consentida da Vila Jordão.

Argumento 1 - Interregno (título provisório), um documentário sobre histórias de famílias da Vila Jordão contadas desde um lapso intergeracional: de um lado, a narração do enredo familiar a partir do ponto de vista dos avós; de outro, a predição desse enredo a partir de seus netos(as). O objetivo é promover uma experiência estética semelhante àquela do pintor espanhol Diego Velázquez com seu quadro "Meninas", ao deslocar os espectadores para um campo intervalar, entre dois regimes distintos de imagens, cada um regido por uma temporalidade única: as imagens do passado (lembradas pelos idosos) e as imagens do presente e futuro (imaginadas pelos jovens) da Vila Jordão. Em cada uma dessas temporalidades (ou regimes de imagens), busca-se

\footnotetext{
${ }^{4}$ Como lembra o antropólogo Eduardo Viveiro de Castro (2016, p. 08), alienígena, como não "natural do lugar em que vive", aquele que se opõe ao indígena, definido não como índio, mas como aquele que é "gerado dentro da terra que lhe é própria, derivação do latim indu arcaico (como endo) > latim clássico in- 'movimento para dentro, de dentro' + gena derivação do radical do verbo gigno, is, genui, genitum, gignere 'gerar"'.
} 
uma profundidade histórica, presentificando não apenas pessoas (mortas ou porvir), mas acontecimentos em espera. A ideia é tanto promover uma ruptura com a imagem (e identidade) de um rural homogêneo que persistente no tempo e no espaço - tal como foi lamentada pelas alegorias do desengano (XAVIER apud TOLENTINO, 2001) - como registrar questões sociais importantes sobre a população rural brasileira como aquelas descritas acima, as quais constituem o pano de fundo de todas essas famílias. Ademais, a profundidade buscada por meio de entrevistas visa romper com os estereótipos dos sujeitos rurais frequentemente representados no cinema brasileiro.

Argumento 2 - Lugar comum (título provisório), documentário sobre a Vila Jordão elaborado a partir de fragmentos de vida de seus moradores. O objetivo é construir um mapa heterogêneo e intenso, um grande mosaico de vidas que têm em comum a maneira singular de experienciar o bairro. Parte-se aqui de uma negação da premissa, parcialmente aceita pelo pensamento moderno, de que expressões como lugar comum ou comunidade constituem espaços de obviedade, lentidão e passividade. A narração de pessoas comuns a descreverem acontecimentos marcantes de suas vidas, suas realizações, superações, as escolhas difíceis, as crises existenciais etc. pretendem não apenas refutar essa premissa, mas criar uma espécie de vinculação com o espectador seja pela identificação com os valores (morais, estéticos etc.) que regem as suas ações, seja pela empatia gerada por suas histórias ou, simplesmente, pela curiosidade que desperta suas presenças no vídeo.

\section{Considerações finais}

Ao longo do projeto CineJordão, buscou-se estudar e desenvolver teorias da comunicação comunitária, da comunicação rural e do cinema à luz da conjuntura histórica e das vivências no bairro. É nesse contexto em que foram formuladas a problematização do conceito de rural, suas representações mediáticas no Brasil, bem como a crítica à sua noção identitária e a busca por estratégias da comunicação rural/comunitária no que diz respeito à visibilidade de suas demandas, à participação dos moradores em projetos comunitários e da ampliação dos vínculos locais. O cinema enquanto instrumento teórico-reflexivo e de mobilização coletiva foi fundamental nesse processo. 
Ademais, desde a sua execução, o cinema foi concebido como atividade comunitária por excelência, já que a produção e a recepção de obras cinematográficas viabilizaram-se pelo trabalho coletivo. As experiências observadas nos grupos escolares demonstraram um empenho comunitário na produção de obras audiovisuais como o sentimento de cooperação e empatia entre os participantes - por exemplo, na transmissão de conhecimento técnico entre pessoas da própria comunidade; ou na paciência que os jovens demonstravam entre si nas atividades de gravação. Mas é no resultado do trabalho coletivo, na fruição das obras audiovisuais produzidas pelos grupos escolares que algo fundamentalmente importante ocorria: a emergência e o reconhecimento de um comum - o rural. Como descreve Gianni Vattimo:

[Nós poderíamos] identificar a experiência do belo com uma experiência vivida de comunidade, que não é nem idêntica ao prazer de uma descoberta científica ou de uma afinidade moral, mas é um sentir-se 'bem' com o nosso próximo na contemplação, ou ainda na apreciação de certos objetos, não enquanto úteis, ou enquanto bons, ou enquanto verdadeiros, e sim justamente enquanto belos (VATTIMO in PAIVA, 2007, p. 64).

Aquela "rebeldia primitiva" que atravessou parte da produção cinematográfica brasileira dos anos de 1960, talvez possa ser pensada hoje nessas composições significantes e sensíveis que desafiam essa modalidade política contemporânea - a biopolítica - que age isolando os sujeitos entre si, direcionando sua energia vital exclusivamente à produção econômica, ou atualizando a gramática do desenvolvimentismo ou do totalitarismo que eventualmente surge em pequenas localidades.

Por outro lado, essa forma de estar junto em uma obra comum tem possibilitado o encontro entre pessoas da escola e do entorno dela, entre jovens que moram em povoados distantes (os chamados "banhados") e vêm à escola para as oficinas promovidas pelo projeto; tem estreitado também o laço social entre comunidades periféricas e a universidade - para muitos desses jovens, a universidade é vista como um lugar inacessível, seja pela distância física (muitos acordam às 4h da manhã para 
chegarem à escola às $8 \mathrm{~h}$ ), seja pela distância simbólica (muitos acreditam que a universidade pública, além do muito difícil o ingresso, não é gratuita) ${ }^{5}$.

Como observou Vattimo, a disposição para o estar junto na fruição do espetáculo cinematográfico indica uma forma de resistência ao poder biopolítico e aos modos de vida por ele codificados. "Muita gente já começa a preferir ir ao cinema do que ver um filme na tela caseira" (In PAIVA, 2007, p. 67).

Até agora, a experiência comunitária aberta pelo Cinejordão (e que talvez outros formatos audiovisuais como a TV não conseguem atingir) diferencia-se pela disposição em povoar e intensificar a própria imagem com diferentes visibilidades e distribuições despertando, inclusive, certa curiosidade municipal ${ }^{6}$. Para o projeto Cinejordão, mais importante do que evidenciar essas imagens é permitir subjetivações em torno delas estimulando produtores e públicos a uma conversação infinita.

A fruição estética dessas obras-não-obras tem sim a ver com uma conciliação, não porém só como futura, mas como vivida no momento, ainda que só ideal, de partilha de uma condição humana e de um 'gosto' que nos une a um mundo concreto dos nossos contemporâneos, na alegria, na tristeza, ou ainda só na espera da realização de uma promessa (VATTIMO In PAIVA, 2007, p. 68).

Se a politização das representações mediáticas do rural no Brasil depende da elaboração de uma multiplicidade sobre ele, a refundação do rural na comunicação como sugeriu Paiva (2017) para a comunicação comunitária - pode ser pensada hoje como possibilidade de abertura a novos arranjos mediáticos que incorpore novas linguagens, tecnologias, imaginários, além de formas contemporâneas de consumo e uso da informação. Não tanto para realizar a teleologia contada pela imagem, mas para mobilizar corpos a instabilizarem o mundo que ela representa.

\footnotetext{
${ }^{5}$ Ao constatar essa elaboração simbólica dos estudantes, o projeto organizou uma visita à Universidade Estadual do Centro Oeste, ocasião em que os estudantes puderam visitar a exposição fotográfica (com fotos tiradas por eles), assistir suas produções cinematográficas com a comunidade universitária e, por fim, ter uma palestra sobre cotas socioeconômicas e as bolsas de permanência na instituição (moradia, vale refeição, transporte, bolsas de pesquisa, ensino e extensão).

${ }^{6} \mathrm{O}$ projeto também tem se preocupado em disseminar suas ações nos principais veículos de comunicação da cidade. O principal jornal impresso, o Correio do Cidadão, veiculou uma reportagem sobre a exibição dos curtas produzidos pelos estudantes iniciando a matéria com o seguinte suspense "Histórias de mistério, aventura e ação. Uma maldição, um alienígena, um assalto e uma pitada de terror".
} 


\section{eCOti
DiAno}

\section{Agradecimentos}

Secretaria da Ciência, Tecnologia e Ensino Superior (SETI-PR); Escola Municipal Enoch Tavares; Colégio Estadual Bibiana Bitencourt; Pró-Reitoria de Extensão e Cultura da Unicentro; Secretaria Municipal de Educação e Cultura de Guarapuava.

\section{Referências bibliograficas}

DIDI-HUBERMAN, Georges. O que vemos, o que nos olha. São Paulo: ed. 34, 2010.

DUARTE, Ricardo; SOARES, Jeferson Boechat. Extensão rural e comunicação rural no Brasil: Notas históricas e desafios contemporâneos. Revista de extensão e estudos rurais. v. 01, n. 2, p. 397-426, 2011.

GOMES, Ivair. O que é rural? Contribuições ao debate. Boletim de Geografia. Maringá, v. 31, n. 3, p. 81-95, 2013.

LIEDKE FILHO. Enno D. A Sociologia no Brasil: história, teorias e desafios. Sociologias, Porto Alegre, Ano 07, n. 14, p. 376-437, jul/dez 2005

MESQUITA, Cláudia. Resistir à morte: a presentificação de João Pedro Teixeira no filme de Eduardo Coutinho. Revista Devires, Belo Horizonte, v. 12, n. 2, p. 38-51, 2015 .

MIGLIORIN, Cezar. Figuras do engajamento: o cinema recente brasileiro. Revista Devires, Belo Horizonte, v. 2, p. 13-27, 2011.

PAIVA, Raquel; BERTOL; Raquel. O desafio de refundar a comunicação comunitária: Raquel Paiva indica as potencialidades e faz um balanço do campo de estudos que consolidou no Brasil. Revista Mídia e Cotidiano. Niterói. v. 11, n. 01, p. 227-236, 2017.

RANCIÈRE, Jacques. O espectador emancipado. São Paulo: Editora WMF Martins Fontes, 2012.

Comunidade como dissentimento. In. DIAS, Bruno P; NEVES, José. (org.). A política dos muitos: Povo, Classes e Multidão. Lisboa: Tinta da China, 2010, p. 425436.

STAVENHAGEN, Rodolfo. Siete tesis equivocadas sobre America Latina. In. STAVENHAGEN, Rodolfo. Sociología y Subdesarrollo. México: Nuestro Tiempo, 1981, p. 15-84. 


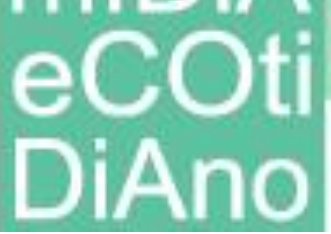

TOLENTINO, Célia Aparecida Ferreira. O rural no cinema brasileiro. São Paulo: Unesp, 2001.

VATTIMO, Gianni. O belo como experiência comunitária. In. PAIVA, Raquel (org). O retorno da comunidade. Rio de Janeiro: Mauad X, 2007, p 63-68.

VIVEIRO DE CASTRO, Eduardo. Os involuntários da pátria. São Paulo: N-1, 2016. 